ORIGINAL ARTICLE

\title{
Leisure time physical activity and strenuousness of work as predictors of physical functioning: a 28 year follow up of a cohort of industrial employees
}

\author{
P Leino-Arjas, S Solovieva, H Riihimäki, J Kirjonen, R Telama
}

Occup Environ Med 2004;61:1032-1038. doi: 10.1136/oem.2003.012054

See end of article for authors' affiliations

Correspondence to:

Dr P Leino-Arjas, Finnish Institute of Occupational Health, Department of Epidemiology and Biostatistics

Topeliuksenkatu 41 a A, FIN-00250 Helsinki,

Finland; paivi.leino-arjas@ Htl.fi

Accepted 28 August 2004

\begin{abstract}
Aims: To examine associations of leisure time physical activity and physical strenuousness of work with physical functioning 28 years later.

Methods: A cohort $(n=902)$ of metal industry employees was studied for exercise and housework activity in 1973 and 1978, and for BMl, current smoking, strenuousness of work, grip strength, and chronic diseases in 1973. Of the 670 survivors in 2000, $529(79 \%)$ responded to all studied items in a follow up questionnaire including the SF-36 Physical Functioning (PF) scale. Belonging to the lower quartile of the PF scale denoted poor functioning.

Results: Vigorous exercise and housework activity were inversely associated with poor PF 28 years later in both white-collar and blue-collar workers. Engaging in activities of any intensity was similarly associated among the blue-collar workers. In a multiple logistic regression model including as independent variables age, sex, occupational class, the number of chronic diseases, vigorous leisure time physical activity, BMI, physical work strenuousness, and smoking (all measured at baseline), the risk of poor PF at follow up was decreased by vigorous leisure time physical activity and increased by high physical strenuousness of work, high BMI, and smoking. The effect of work strenuousness was mainly due to that among the blue-collar group. Allowing for baseline grip strength did not materially alter the results.

Conclusion: Vigorous leisure time physical activity decreased the risk of poor physical functioning as perceived considerably later in life, while high work strenuousness, smoking, and overweight increased it. Among blue-collar workers a beneficial association was observed with all leisure time activity, including that of lower intensity.
\end{abstract}

A dequate physical functioning is needed for the independent management of basic daily activities, self-care, and transportation, and is a prerequisite for the attainment of many higher level goals. It is thus a core component of good quality of life.

Leisure time physical activity has multifaceted effects on health ${ }^{1-5}$ and contributes to maintaining normal muscle strength, joint function, and physical functioning. ${ }^{15-7}$ The required intensity and duration of activity to reach various health benefits is debated, but current opinion underlines the public health importance of moderate intensity activity. ${ }^{5}$

A demonstration of a relation of leisure time physical activity with physical functioning over a longer time-span is complicated by variation in possible intervening factors influencing the possibilities or motivation to engage in physical activity, as well as physical functioning, such as socioeconomic status, other components of lifestyle, and health. Physical activity also generally decreases with ageing..$^{8} 9$

It is customary in most societies for women to carry by far the bigger burden of housework. Among women, on average, domestic housework activities constitute a major part of regular physical activity, ${ }^{10}$ and should be taken into account when examining relations between physical activity and health outcomes.

Occupationally active people are more or less physically active at work. High physical strenuousness of work tasks is mostly considered as increasing the risk of musculoskeletal disorders ${ }^{11}{ }^{12}$ that may lead to poor physical functioning. ${ }^{13}$ While physical activity at work, as well as during leisure, is generally linked with better cardiovascular health, excessive work demands, particularly when connected with low job control, constitute a risk for cardiovascular disease. ${ }^{14}$

We studied the long term associations of leisure time physical activity and strenuousness of work with selfreported physical functioning in a cohort representative at baseline of white-collar and blue-collar employees in an engineering company. Regarding leisure time activities, both the whole range of energy expenditure and specifically vigorous activity in exercising and housework were studied. As potential confounders we considered sociodemographic variables, existing chronic diseases, smoking, relative body mass, and grip strength as a proxy for fitness.

\section{METHODS}

\section{Data collection}

The present study is part of a research programme with the general aim to examine work related exposures, fitness, and lifestyle factors as determinants of the development in health. The study sample was drawn from among the employees of the Valmet engineering company in Jyväskylä, Central Finland. The study population comprised those employed by Valmet for at least 15 months in January 1973 $(n=2653)$. A systematic sampling according to strata by sex (two thirds were men), age group (born before 1925 (33\%), $1926-45(39 \%)$, and 1946 or later $(28 \%))$, and occupational class (upper/lower white-collar (44\%), skilled/semi-skilled workers $(56 \%))$ was made. People who refused to participate were replaced with the one next in order on a reserve list (155

Abbreviations: BMI, body mass index; LTPA, leisure time physical activity; PF, Physical Functioning scale 


\section{Main messages}

- Vigorous leisure time physical activity was associated with reduced risk of poor physical functioning later in life among both white-collar and blue-collar employees.

- Leisure time physical activity of any intensity showed an inverse relation with poor functioning among bluecollar workers.

- High physical strenuousness of work, overweight, and smoking were predictive of later poor physical functioning.

replacements were made). In the spring of 1973, 902 subjects participated in an examination by questionnaire, interview of physical activity, and clinical investigations. ${ }^{15}$

Figure 1 presents the design and participation activity in three follow up examinations of the cohort. The present analyses concern primarily the baseline and the last follow up $(n=546)$. A subanalysis was made among those who participated in both the first and the last follow up $(\mathrm{n}=457)$. As of 30 November 2000, 232 subjects belonging to the cohort had died, 108 of these for cardiovascular causes. Of the survivors, $546(81.5 \%)$ took part in a re-examination questionnaire survey in the turn of 2000 and 2001 (74.0\% in the oldest, $86.0 \%$ in the middle, and $80.9 \%$ in the youngest age group).

\section{Measurements at baseline}

Leisure time physical activity (LTPA) was measured using a two phase checklist and interview method following Montoye and Epstein ${ }^{16}$ and Reiff and colleagues. ${ }^{17}$ First, the subjects responded to a 51 item checklist including leisure time physical activities and housework activities typical for urban Finnish adults. Two categories of activity were considered: (1) sports, exercise, and physical recreation; and (2) household chores. The examinees were asked to check all activities of any frequency or duration in which they had participated during the past 12 months. Space for other activities was reserved in the list. Second, the subjects were interviewed for 15-20 minutes by trained research assistants. The subjects reported the frequency, duration, and intensity of each activity marked on their list. Intensity (three grades: low $=$ neither getting out of breath nor perspiring; moderate $=$ to some extent getting out of breath and perspiring; high $=$ getting severely out of breath and perspiring heavily) was only asked about for activities in which it can vary (for example, asked for walking, but not for dishwashing). Seasonal variation, sick leaves, and other deviations from routine practice were inquired about in order to obtain an estimate of the total time spent on each activity during the past year. The reported intensity as well as the average energy expenditure (coefficients obtained from the literature) of each activity were taken into account in the scoring.

Two indicators of LTPA were constructed:

- Total exercise and housework activity refers to the product sum of the time spent on exercise and household chores, each multiplied in turn by its energy consumption (coefficient estimates)

- Vigorous exercise and housework activity refers to the product sum of the time spent on those physical activities and household chores in which the energy expenditure exceeded $500 \mathrm{kcal} / \mathrm{hour}$, each multiplied in turn by its energy consumption (above that limit).

\section{Policy implications}

- Leisure time physical activity as a component of a healthy lifestyle should be encouraged among both white-collar and blue-collar employees.

- Decreasing physical work strenuousness may enhance later physical functioning.

The reliability of the assessment was studied by comparing the estimates of time spent in LTPA as based on the interview and on a diary of time usage with an accuracy of 15 minutes for two weekdays and one Saturday and Sunday. The two methods gave highly similar results. The interviewers, though different persons at different follow ups, were trained for the interview by the same senior scientist on each occasion. The assessment method of LTPA is discussed in more detail elsewhere. ${ }^{18}$ All subjects at baseline $(\mathrm{n}=902)$ underwent the assessment of LTPA. For the logistic regression analyses, total exercise and housework activity was put to tertiles. Vigorous exercise and housework activity was dichotomised (no/yes).

Current regular smoking was classified as yes/no. One subject had missing information on smoking status.

Weight was measured to the accuracy of $0.1 \mathrm{~kg}$ in light sportswear and without shoes. Height was self-reported. Body mass index (BMI; $\mathrm{kg} / \mathrm{m}^{2}$ ) was available for all subjects and was put to tertiles for analysis.

The questionnaire inquired: "How physically strenuous do you consider your work on average?" The respondent was asked to tick a number on a Borg scale from 6 to 20 (from very, very light to very, very strenuous) as appropriate with the subject's own physical capacity as reference. The response was used as the indicator of the physical strenuousness of work. In the total material the scale was trichotomised (as near to tertiles as possible) as $6-10=$ low, $11-13=$ medium, and 14-19 =high. In an analysis within a restricted sample

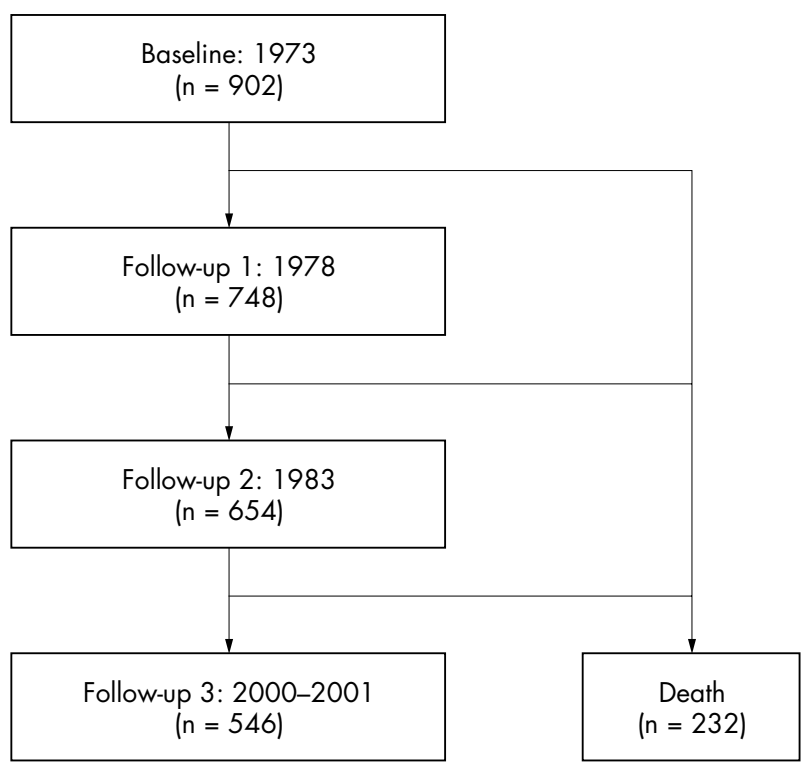

Figure 1 Participation in the three follow ups among the cohort. Of the 232 deaths, 12 occurred during 1973-78, 29 during 1978-83, and 190 during 1983-2000. In 1973, 1978, and 1983 the figures refer to those who both returned a questionnaire and took part in a clinical examination and interview. In 2000, 546 subjects returned the questionnaire. Of these, 439 also participated in a clinical examination, including an interview of leisure time physical activity. 
without chronic diseases the scale was dichotomised as 6$10=$ low, $11-19=$ other. In stratified analyses by occupational class the following class limits were used: 7-12, 13-14, 15-19 for the blue-collar and 6-9, 10-11, 12-16 for the whitecollar employees. There were four subjects with missing information on work strenuousness.

Occupational class was dichotomised to white-collar and blue-collar workers.

Information on the occurrence of chronic disorders was available for all subjects. The questionnaire inquired: "Have you any long standing or permanent disease or disability?" Additional questions inquired the kind of disease up to four diseases. A physician classified the labels according to the ICD-8 on a three digit level. The number of disorders was recorded and classified as $0=$ none, $1=$ one, $2=2$ or more.

Grip strength of all subjects was measured twice from each hand with a hand dynamometer. ${ }^{15}$ The best result was used in the analyses.

\section{Follow up in 1978}

The assessment of LTPA and physical strenuousness of work were similar to those at baseline (see above). Vigorous exercise and housework activity in 1978 was used in a subanalysis concerning the stability of LTPA. Six subjects of the 748 that participated in the follow up had missing information on this variable.

\section{Follow up in 2000}

Physical functioning was assessed using the Medical Outcomes Study Short Form Questionnaire (SF-36) Physical Functioning Scale (PF). Information on it was available for 532 subjects. The 10 items cover limitations in strenuous and moderately strenuous activities in general and more specifically in climbing stairs, walking, bending or kneeling, and in daily activities such as carrying bags, washing, or dressing. Each item is scored from 1 to 3 and summed. A high score represents good physical functioning. The scale has been shown to have good psychometric properties. ${ }^{19}$ We dichotomised the sum scale with the low $25 \%$ of the distribution as the cut point.

Respondents under 65 years of age (the general pensioning age in Finland) were asked about their current working status using the alternatives: $1=$ full-day work, $2=$ shortened work week, $3=$ part time job, $4=$ temporarily laid off, $5=$ unemployed, $6=$ part time pension, $7=$ early pension,
$8=$ disability pension, $9=$ for other causes outside the workforce. The categories 1-4 were considered to represent those still in working life.

\section{Statistical methods}

The associations of the PF score with the year of birth were described with Pearson correlation coefficients. Otherwise categorised age with the class limits of the original strata was used.

The means and standard errors of the two measures on LTPA, strenuousness of work, and the covariates, by sex and occupational class were calculated. The association between physical work strenuousness and LTPA were described with Pearson correlation coefficients.

Logistic regression analysis was used in the main analyses that described the associations of variables measured at baseline (LTPA, strenuousness of work, and the covariates BMI, smoking, age, sex, occupational class, and the number of chronic disorders) with the PF score in the 28 year follow up. First, age adjusted analyses were made. Second, mutually adjusted models were calculated, separately for the two measures of LTPA. Third, the mutually adjusted models were recalculated in the subgroup where subjects with chronic diseases at baseline were excluded.

In addition, logistic regression models including grip strength among the independent variables were examined. We also studied the relations of the two measures of LTPA with PF with models made separately for the white-collar and blue-collar employees.

Information on all variables at baseline and at the 28 year follow up was available for 529 subjects (79\% of the 670 subjects alive in the cohort). Among the subjects who participated in both the five year and the 28 year follow up studies ( $n=457$ or $68 \%$ of those alive in 2000 ), we examined the five year stability of vigorous LTPA and work strenuousness with Pearson correlation coefficients. The significance of stability of vigorous LTPA and work strenuousness regarding their associations with physical functioning was studied by logistic regression.

\section{RESULTS}

The age of the 529 subjects included in the analyses was 1764 years (mean 34.6) at baseline (mean 62.6 at follow up). The PF score measured at follow up ranged from 10 to 30 , with a mean of 23.4 (SD 5.2) in women and 25.5 (5.2) in men

\begin{tabular}{|c|c|c|}
\hline & $\begin{array}{l}\text { Women }(n=183) \\
\text { Mean (SE) }\end{array}$ & $\begin{array}{l}\text { Men }(n=346) \\
\text { Mean (SE) }\end{array}$ \\
\hline $\begin{array}{l}\text { Total exercise and housework activity } \\
\text { Vigorous exercise and housework activity } \\
\text { Physical strenuousness of work } \\
\text { BMI } \\
\text { Current smokers (yes, \%) } \\
\text { Chronic disease (yes, \%) } \\
\text { Grip strength (Kp) }\end{array}$ & $\begin{array}{r}2793.0(92.1) \\
135.7(23.6) \\
12.1(0.19) \\
23.9(0.27) \\
16.9(0.03) \\
33.9(0.04) \\
37.5(0.34)\end{array}$ & $\begin{aligned} 2025.2(72.7) \\
262.8(22.0) \\
12.0(0.16) \\
24.6(0.16) \\
26.7(0.02) \\
32.5(0.03) \\
62.1(0.49)\end{aligned}$ \\
\hline & $\begin{array}{l}\text { White-collar ( } n=258 \text { ) } \\
\text { Mean (SE) }\end{array}$ & $\begin{array}{l}\text { Blue-collar }(n=271) \\
\text { Mean (SE) }\end{array}$ \\
\hline $\begin{array}{l}\text { Total exercise and housework activity } \\
\text { Vigorous exercise and housework activity } \\
\text { Physical strenuousness of work } \\
\text { BMI } \\
\text { Current smokers (yes, \%) } \\
\text { Chronic disease (yes, \%) } \\
\text { Grip strength (Kp) }\end{array}$ & $\begin{array}{r}2257.6(80.3) \\
264.5(26.3) \\
10.2(0.14) \\
24.0(0.19) \\
17.8(0.02) \\
26.7(0.03) \\
51.3(0.84)\end{array}$ & $\begin{array}{r}2316.2(87.3) \\
176.2(20.8) \\
13.8(0.13) \\
24.6(0.21) \\
28.7(0.03) \\
37.6(0.03) \\
55.7(0.87)\end{array}$ \\
\hline
\end{tabular}


$(\mathrm{p}<0.001)$, and $25.8(4.9)$ in white-collar and 23.8 (5.5) in blue-collar workers $(\mathrm{p}<0.001)$. The age gradient in the score was steep ( $r$ with the year of birth: 0.51 in women and 0.47 in men).

Of the subjects taking part in the follow up in 2000, 352 $(66 \%)$ were under 65 years of age. Of these, $75 \%$ were still in working life ( $11 \%$ unemployed), $21 \%$ were on some type of early pension ( $7 \%$ on disability pension), and $4 \%$ were outside the workforce for other reasons.

Table 1 presents the mean values of the LTPA variables, strenuousness of work, and covariates by sex and occupational class. The association between physical work strenuousness and LTPA was low (vigorous activity: $r=-0.08$ in the total material and 0.03 in the blue-collar workers; all activity, respectively: $r=0.07$ and 0.07 ).

\section{Strenuousness of work and LTPA at baseline in relation to physical functioning in the 28 year follow up}

Table 2 presents age adjusted associations of baseline vigorous exercise and housework activity and covariates with poor PF at follow up, and a mutually adjusted model. According to the model, vigorous exercise and housework activity at baseline was protective of poor PF at follow up (OR $0.42 ; 95 \%$ CI 0.26 to 0.68 ), while physical strenuousness of work at baseline was associated with poor functioning (high $v$ low strenuousness: $2.40,95 \%$ CI 1.07 to 5.41 ). In addition, increasing age, female sex, having several chronic disorders, high BMI, and being a regular smoker increased the risk of poor PF 28 years later.

\section{Effect of chronic diseases}

Of the 529 subjects included in the analyses, 171 reported some chronic disease. The most common were those of the low back, reported by 35 subjects (6.6\%). Thirty persons $(5.7 \%)$ reported some cardiovascular disease, of which hypertension was the most prevalent. Eleven subjects $(2.1 \%)$ had a chronic infection of the upper respiratory tract or allergic rhinitis, and eight (1.5\%) had asthma, chronic bronchitis, or emphysema.

When the subjects with any chronic disorder at baseline were excluded from analyses, the basic results were largely retained. Vigorous exercise and housework activity at baseline was inversely associated with poor PF at follow up (0.33, 95\% CI 0.17 to 0.61 ), adjusted for age, sex, occupational class, smoking, BMI, and physical strenuousness of work. In the model, the odds ratio for the dichotomised work strenuousness variable was 2.29 (95\% CI 1.01 to 5.21 ).

\section{Effect of grip strength}

In all available subjects $(n=529)$, the OR of a poor PF score at follow up for the highest versus lowest tertile of baseline grip strength was 2.89 (95\% CI 0.98 to 8.51), adjusted for age and gender. When grip strength was added among the independent variables in the multivariate model (table 2) the results remained largely the same: the OR for vigorous exercise and housework activity was 0.44 (95\% CI 0.27 to $0.71)$ and for the high versus low work strenuousness 2.36 (95\% CI 1.05 to 5.29 ).

\section{Stratified analyses by occupational class}

The associations between vigorous activity and poor PF were similar in both occupational classes (table 3 ) and sexes (data not shown).

In the fully adjusted model (table 2) blue-collar occupational class was not associated with poor functioning. This was mainly due to the effect of the work strenuousness variable. Without the latter included, blue-collar occupational class doubled the odds ratio of poor functioning (1.97; 95\% CI 1.15 to 3.39). Stratified by occupational class and using class specific categorisation, strenuousness of work at baseline increased the risk of poor PF at follow up in the fully adjusted model in the blue-collar group (medium strenuousness $v$ low: $2.21,95 \%$ CI 0.81 to 6.05 ; high $v$ low: $3.08,95 \%$ CI 1.18 to 8.09 ). Among the white-collar employees in the intermediate and high categories of work strenuousness the risk of poor

\begin{tabular}{|c|c|c|c|}
\hline & \multirow[b]{2}{*}{ n (cases) } & \multicolumn{2}{|c|}{ Poor physical functioning } \\
\hline & & $\begin{array}{l}\text { Adjusted for age } \\
\text { OR }(95 \% \mathrm{CI})\end{array}$ & $\begin{array}{l}\text { Mutually adjusted* } \\
\text { OR }(95 \% \mathrm{CI})\end{array}$ \\
\hline \multicolumn{4}{|c|}{$\begin{array}{l}\text { Vigorous exercise and housework } \\
\text { activity }\end{array}$} \\
\hline No & $222(78)$ & 1.00 & 1.00 \\
\hline Yes & $307(52)$ & $0.34(0.22$ to 0.53$)$ & 0.42 (0.26 to 0.68$)$ \\
\hline \multicolumn{4}{|c|}{ Physical strenuousness of work } \\
\hline Low & $154(21)$ & 1.00 & 1.00 \\
\hline Medium & $210(55)$ & 2.50 (1.38 to 4.52$)$ & 1.96 (0.98 to 3.92$)$ \\
\hline High & $165(54)$ & $3.50(1.91$ to 6.43$)$ & 2.40 (1.07 to 5.41$)$ \\
\hline \multicolumn{4}{|c|}{0.00 (1.1. } \\
\hline Men & 346 (67) & 1.00 & 1.00 \\
\hline Women & $183(63)$ & 1.95 (1.26 to 3.02 ) & 2.38 (1.43 to 3.95 ) \\
\hline \multicolumn{4}{|c|}{ Occupational class } \\
\hline White-colla & $258(47)$ & 1.00 & 1.00 \\
\hline Blue-collar & 271 (83) & 2.58 (1.65 to 4.05$)$ & 1.36 (0.73 to 2.53$)$ \\
\hline \multicolumn{4}{|c|}{ Number of chronic disorders } \\
\hline None & $358(67)$ & 1.00 & 1.00 \\
\hline One & $121(34)$ & $1.31(0.79$ to 2.17$)$ & 0.95 (0.54 to 1.66$)$ \\
\hline$\geqslant 2$ & $50(29)$ & 3.18 (1.62 to 6.26$)$ & 2.77 (1.30 to 5.89$)$ \\
\hline \multicolumn{4}{|l|}{ BMl† } \\
\hline Low & $176(20)$ & 1.00 & 1.00 \\
\hline Medium & 177 (38) & $1.60(0.86$ to 2.96$)$ & $1.89(0.98$ to 3.66$)$ \\
\hline High & $176(72)$ & 3.02 (1.66 to 5.48 ) & 3.57 (1.84 to 6.90$)$ \\
\hline \multicolumn{4}{|l|}{ Smoking } \\
\hline No & 405 (92) & 1.00 & 1.00 \\
\hline Yes & 124 (38) & $1.87(1.15$ to 3.05$)$ & 2.16 (1.24 to 3.76$)$ \\
\hline
\end{tabular}


Table 3 Total and vigorous exercise and housework activity at baseline in relation to poor physical functioning (SF-36) at follow up, by occupational class; logistic regression analysis

\begin{tabular}{|c|c|c|c|c|}
\hline & \multicolumn{2}{|c|}{ White-collar } & \multicolumn{2}{|c|}{ Blue-collar } \\
\hline & n (cases) & OR $(95 \% \mathrm{Cl})$ & $\mathrm{n}$ (cases) & OR $(95 \% \mathrm{Cl})$ \\
\hline \multicolumn{5}{|c|}{$\begin{array}{l}\text { Total exercise and housework } \\
\text { activity* }\end{array}$} \\
\hline Low & $86(16)$ & 1.00 & $90(33)$ & 1.00 \\
\hline Medium & $86(18)$ & $0.97(0.39$ to 2.39$)$ & $91(33)$ & $0.67(0.31$ to 1.46$)$ \\
\hline High & 86 (13) & $0.86(0.33$ to 2.26$)$ & $90(17)$ & 0.27 (0.11 to 0.65 ) \\
\hline \multicolumn{5}{|c|}{$\begin{array}{l}\text { Vigorous exercise and housework } \\
\text { activity }\end{array}$} \\
\hline No & $81(24)$ & 1.00 & $141(54)$ & 1.00 \\
\hline Yes & $177(23)$ & $0.38(0.19$ to 0.76$)$ & $130(29)$ & $0.46(0.25$ to 0.85$)$ \\
\hline
\end{tabular}

functioning was also increased compared with those with low strenuousness, but not statistically significantly (medium $v$ low: $2.06,95 \%$ CI 0.87 to 4.90 ; high $v$ low: $1.92,0.77$ to $4.81)$.

When total exercise and housework activity was studied, the highest activity tertile had a decreased risk of poor PF at the 28 year follow up compared with the lowest $(0.44 ; 95 \%$ CI 0.23 to 0.84 ), adjusting for covariates as in table 2 . The association was mainly due to that among the blue-collar workers (tables 3 and 4).

\section{Effect of stability of work strenuousness and LTPA}

The stability of physical strenuousness of work was high as reflected by the correlation coefficient $(r=0.69)$ of the scale measured at baseline and in the five year follow up $(n=457)$. Those who belonged to the highest tertile of the score both at baseline and at the five year follow up had a higher risk of poor functioning $(3.08$; $95 \%$ CI 1.15 to 8.21 , adjusting for age, sex and occupational class) than those who belonged to the lowest tertile on both occasions (the group with changes in score tertile: $1.57 ; 95 \%$ CI 0.70 to 3.53 ).

Leisure time physical activity was less stable (vigorous activity: $r=0.32$ ). However, it was observed that those who engaged in vigorous exercise or housework both at baseline and at the five year follow up had a clearly decreased risk of poor $\mathrm{PF}$ at the 28 year follow up compared with those who reported vigorous activity on neither occasion (OR 0.29; 95\% CI 0.16 to 0.55 , adjusted for age, sex and occupational class), while those who reported vigorous exercise either at baseline

Table 4 Associations of total exercise and housework activity and strenuousness of work at baseline with poor physical functioning (SF-36) at follow up among bluecollar workers; multiple logistic regression model*

\begin{tabular}{|c|c|c|c|}
\hline & \multicolumn{3}{|c|}{ Poor physical functioning } \\
\hline & n (cases) & OR & $(95 \% \mathrm{Cl})$ \\
\hline \multicolumn{4}{|c|}{$\begin{array}{l}\text { Total exercise and housework } \\
\text { activityt }\end{array}$} \\
\hline Low & $90(33)$ & 1.00 & \\
\hline Medium & 91 (33) & 0.70 & $(0.30$ to 1.60$)$ \\
\hline High & 90 (17) & 0.24 & $(0.10$ to 0.66$)$ \\
\hline \multicolumn{4}{|c|}{ Strenuousness of work $\ddagger$} \\
\hline Low & $59(9)$ & 1.00 & \\
\hline Medium & $92(31)$ & 2.41 & (0.87 to 6.69 ) \\
\hline High & $120(43)$ & 3.61 & (1.35 to 9.51$)$ \\
\hline \multicolumn{4}{|c|}{$\begin{array}{l}\text { *Independent variables: total exercise and housework activity, } \\
\text { strenuousness of work, age, sex, number of chronic disorders, BMI, and } \\
\text { smoking at baseline. } \\
\text { †Tertiles among the blue-collar group. } \\
\text { †Borg scale categorised as } 7-12=\text { low, } 13-14=\text { medium, 15-19= high. }\end{array}$} \\
\hline
\end{tabular}

or at the five year follow up were an intermediate category (0.57; $95 \%$ CI 0.33 to 0.98$)$.

\section{DISCUSSION}

In this study, physical functioning was assessed in terms of related quality of life. The physical functioning scale of the widely used Medical Outcomes Study SF-36 instrument defines good quality of life as the absence of physical limitation or disability. The scale reflects mostly variation in physical health ${ }^{19}$ and is associated with established disease risk factors. ${ }^{20}$ The SF-36 scale was not available at the study start in 1973. We were not able to construct an indicator of change in physical functioning over time, but looked at associations of physical activity and work strenuousness, and other predictor variables, with physical functioning 28 years later. However, all subjects were occupationally active at baseline, indicating minimal disability.

We found that high physical strenuousness of work increased the risk of later poor functioning, while leisure time physical activity was protective of it. The associations were independent of each other. They were also robust and not materially affected by adjustment for several covariates at baseline. Of the studied covariates, high BMI, smoking, and female sex, in addition to existing chronic diseases, increased the risk of poor physical functioning. All observations are in accordance with previous reports..$^{20-22}$

The basic results were retained when existing chronic diseases were allowed for in the multivariate analyses and when these were repeated in the subgroup without chronic diseases. Thus, the association of leisure time physical activity with physical functioning did not seem to be due to original health differences between those more versus less active. With time, the health status among the subjects with varying physical activity probably increasingly diverged, as cardiovascular and other health differences developed. Incident diseases might, of course, lead to a decline in physical functioning.

Some previous findings support a long standing association of physical activity with physical functioning. The lower selfreported disability rate in the members of a runners' club aged 50 years and older as compared with controls was sustained in a 13 year follow up..$^{23}$ Among British men aged 40-59 years, physical inactivity was associated with locomotor disability 12-14 years later, allowing for other lifestyle characteristics and social class. ${ }^{24}$ When three levels of health risks were defined based on smoking, body mass index, and vigorous exercise patterns among former university alumni, those with high risk had twice the cumulative disability of those with low risk over 12 years. ${ }^{25}$ In a 10 year follow up of elderly women and men from three US communities, 
physical activity was a key factor predicting non-disability before death. ${ }^{26}$

During the long follow up, 232 subjects of the cohort died, 108 of them for cardiovascular causes. The material represented the survivors well, due to the good response rate. Those with high leisure time physical activity tend to live longer. ${ }^{12}$ High leisure time physical activity was protective of cardiovascular death among our cohort. ${ }^{27}$ This means that survival in the cohort was selective, favouring those initially more active. Increased selection of subjects with low baseline activity out of the cohort through death may have diluted associations of activity with physical functioning. The higher non-response rate in the follow up of older subjects may have a similar effect, although the difference here was not large (among the survivors the participation rate was $74 \%$ in the oldest, $86 \%$ in the middle, and $81 \%$ in the youngest age group).

Could differences in original fitness between the physically active and less active be an explanation for the observed relations of activity and work strenuousness with physical functioning? This was studied by using grip strength as a proxy for fitness. Grip strength has been observed to be inversely associated with mortality among initially healthy men $^{28}$ and to predict future functional ability. ${ }^{29}$ In our analyses, taking the baseline value of grip strength into account had little effect on the associations of physical activity and physical functioning. It seems that confounding by fitness differences at baseline does not account for the results.

Several possible mechanisms might be suggested for an association between leisure time physical activity and physical functioning. First, the association may arise from the fact that those who are fit and have good physical functioning also tend to exercise more than the less fit. Genetic constitutional factors have been implied as possibly predisposing for both physical activity and physical functioning. ${ }^{30}$ On the other hand, the results may directly reflect the effects of physical activity on the function of joints, muscles, and other components of the musculoskeletal system. ${ }^{1}$ Another factor to take into account is that self-efficacy may influence perceptions of functional ability independent of actual physical abilities. ${ }^{31}$ It has been suggested that physical activity favourably influences self-efficacy, self-esteem, and confidence in physical functioning. ${ }^{7}$

Perceived physical strenuousness of work was associated with poor functioning, showing an exposure-response pattern. This association was also relatively insensitive to adjustment for the covariates, including grip strength. Work strenuousness was not predictive of mortality, and loss to follow up through death was of little importance here regarding the strength of the relation.

Although a considerable number of changes in work tasks and working status had occurred among the respondents, a clear pattern of associations with physical functioning emerged. This implies considerable stability in the determinant over time. There was a high correlation of work strenuousness measured at baseline and at the five year follow up. Later during the follow up this necessarily decreased. At the Valmet company a relative stability of employment ceased at the end of the 1980s, after which the study subjects were widely dispersed in various workplaces in the region. Only half of the sample belonged to the workforce in 2000.

Why were associations of physical functioning with physical strenuousness of work, on the one hand, and with leisure time physical activity, on the other, of opposite direction? Physical activity at work and during leisure differ in many respects. The type, timing, duration, and intensity of the latter may be chosen by the individual. Loading at work is usually of a considerably longer duration, more repetitive and monotonous, and less under the control of the performer than exercise or housework. High subjective strenuousness of work tasks increased the risk of poor functioning, particularly in the blue-collar stratum of the cohort, in which very heavy tasks occurred, particularly in the foundry. The workers performed melting and casting of metal, kernel core setting, forging, welding, powering and tooling, milling, turning, drilling, and filing, as well as assembly and maintenance work. In such jobs work demands may exceed the physical capacity of the worker, leading to negative health effects in the long term. ${ }^{32}$ Discrepancies between individual physical capacity and physical demands of work are not infrequent, even in today's work life..$^{33} 34$

White-collar employees engaged in vigorous leisure time activities more often than blue-collar workers, in agreement with other findings, ${ }^{35}$ while total physical activity did not differ by occupational class. Vigorous activity was associated with good functioning in both occupational groups, but the overall score was protective of poor physical functioning only among the blue-collar workers. Among them, an exposureresponse pattern was visible. Thus it seems that in those doing physical work, even moderate activity during leisure is enough, while among those in sedentary work, activity should be more energy consuming for delaying a decrease of functioning.

We observed that the association of occupational class with physical functioning persisted when allowing for lifestyle characteristics and chronic diseases. Similar findings have been reported before. ${ }^{36}$ However, the association was considerably reduced when physical strenuousness of work was accounted for in the modelling. Then, in this cohort, occupational class differences in physical functioning were largely due to physical workload. The contribution of physical work characteristics to social class differentials in health have been little studied. However, in a large sample of the working Dutch population it was observed that a substantial part of the association between occupational class and poor perceived general health could be attributed to a differential distribution of hazardous physical working conditions and low job control across occupational classes. ${ }^{37}$

In conclusion, it seems that engaging in exercise-like activities and housework, particularly of higher intensity, during midlife, is favourably reflected in physical functioning decades later in older adulthood, while high strenuousness of work is associated with later poor functioning. The exact mechanisms of these associations remain to be elucidated.

\section{ACKNOWLEDGEMENTS}

The study was supported by the Academy of Finland (project number 70139) and the Ministry of Education, Finland (188/722/2000 and 146/722/2001).

\section{Authors' affiliations}

P Leino-Arjas, S Solovieva, H Riihimäki, Department of Epidemiology and Biostatistics, Finnish Institute of Occupational Health, Helsinki, Finland

J Kirionen, R Telama, Department of Physical Education, University of Jyväskylä, Finland

Ethical approval: Ethical approval for the study was obtained from the Hospital District of Helsinki and Uusimaa Ethics Committee for Research in Occupational Health and Safety. The subjects gave a written, informed consent of participation in the study.

\section{REFERENCES}

1 US Department of Health and Human Services. Physical activity and health: a report of the Surgeon General. Atlanta, GA: US Department of Health and Human Services, Centers for Disease Control and Prevention, National Center for Chronic Disease Prevention and Health Promotion, 1996. 
2 Andersen LB, Schnohr P, Schroll M, et al. All-cause mortality associated with physical activity during leisure time, work, sports, and cycling to work. Arch Intern Med 2000;160:1621-8.

3 Sesso HD, Paffenbarger RSJ, Lee I-M. Physical activity and coronary heart disease in men. The Harvard Alumni Health Study. Circulation 2000;102:975-80.

4 Strawbridge WJ, Deleger S, Roberts RE, et al. Physical activity reduces the risk of subsequent depression for older adults. Am J Epidemio/ 2002;156:328-34.

5 Thompson PD, Buchner D, Pina IL, et al. Exercise and physical activity in the prevention and treatment of atherosclerotic cardiovascular disease: a statement from the Council on Clinical Cardiology (Subcommittee on Exercise Rehabilitation, and Prevention) and the Council on Nutrition, Physical Activity, and Metabolism (Subcommittee on Physical Activity). Circulation 2003:107:3109-16.

6 Rejeski WJ, Mihalko SL. Physical activity and quality of life in older adults. J Gerontol Series A 2001;56A(special issue II):23-35.

7 Spirduso WW, Cronin L. Exercise dose-response effects on quality of life and independent living in older adults. Med Sci Sport Exerc 2001;33:S598-608.

8 Verbrugge LM, Gruber-Baldini AL, Fozard JL. Age differences and age changes in activities: Baltimore Longitudinal Study of Aging. J Gerontol Soc Sci 1996;51B:S30-41

9 Bïnen FCH, Feskens EJM, Caspersen CJ, et al. Age, period, and cohort effects on physical activity among elderly men during 10 years of follow-up: the Zutphen Elderly Study. J Gerontol Med Sci 1998;53A:M235-41

10 Lawlor DA, Taylor M, Bedford C, et al. Is housework good for health? Levels of physical activity and factors associated with activity in elderly women. Results from the British Women's Heart and Health Study. J Epidemiol Community Health 2002;56:473-8.

11 Hoogendoorn WE, van Poppel MN, Bongers PM, et al. Physical load during work and leisure time as risk factors for back pain. Scand J Work Environ Health 1999;25:387-403.

12 Riihimäki H, Viikari-Juntura E. Back and limb disorders. In: McDonald JC, ed. Epidemiology of work related diseases, 2nd edn. Bristol: BMJ Publishing Group, 1999:233-65.

13 Mäkelä M, Heliövaara M, Sievers K, et al. Musculoskeletal disorders as determinants of disability in Finns aged 30 years or more. $J$ Clin Epidemiol 1993;46:549-59.

14 Steenland K, Fine L, Belkic K, et al. Research findings linking workplace factors to CVD outcomes. Occup Med 2000;15:7-68

15 METELI. Health examination. Sampling, methods and implementation [in Finnish with English summary]. Jyväskylä: Publications of the Research Institute of Physical Culture and Health, No. 9, 1975.

16 Montoye HJ, Epstein FH. Tecumseh community health study: an investigation of health and disease in an entire community. J Sports Med Phys Fitness 1965;5:127-31.

17 Reiff GG, Montoye HJ, Remington RD, et al. Assessment of physical activity by questionnaire and interview. In: Karvonen MJ, Barry AJ, eds. Physical activity and the heart. Springfield: Charles C. Thomas, 1967:336-71.

18 Telama R. Measurement of physical activity. In: Leino P, Hänninen V, Toivonen $\mathrm{L}$, et al. Working conditions, mental well-being, living habits, and health among occupational groups in the metal industry in 1973-83. Study design and implementation [in Finnish]. Tampere: Kansanterveystieteen julkaisuja M82/84, 1984
19 Ware JE, Gandek B. Overview of the SF-36 Health Survey and the International Quality of Life Assessment (IQOLA) Project. J Clin Epidemiol 1998;51:903-12.

20 Stafford M, Hemingway $H$, Stansfeld SA, et al. Behavioural and biological correlates of physical functioning in middle aged office workers: the UK Whitehall II study. J Epidemiol Community Health 1998;52:353-8.

21 Larsson U, Karlsson J, Sullivan M. Impact of overweight and obesity on healthrelated quality of life-a Swedish population study. Int J Obes Relat Metab Disord 2002;26:417-24.

22 Leveille SG, Resnick HE, Balfour J. Gender differences in disability: evidence and underlying reasons. Aging (Milano) 2000;12:106-12.

23 Wang BW, Ramey DR, Schettler JD, et al. Postponed development of disability in elderly runners: a 13-year longitudinal study. Arch Intern Med 2002; 162:2285-94

24 Ebrahim S, Wannamethee SG, Whincup P, et al. Locomotor disability in a cohort of British men: the impact of lifestyle and disease. Int J Epidemiol 2000;57:478-86.

25 Vita AJ, Terry RB, Hubert HB, et al. Aging, health risks and cumulative disability. N Engl J Med 1998;338:1035-41.

26 Leveille SG, Guralnik JM, Ferrucci L, et al. Aging successfully until death in old age: opportunities for increasing active life expectancy. Am J Epidemiol 1999; 149:654-64

27 Kivimäki M, Leino-Arjas P, Luukkonen R, et al. Work stress and risk of cardiovascular mortality: prospective cohort study of industrial employees. BMJ 2002;325:857.

28 Rantanen T, Harris T, Leveille S, et al. Muscle strength and body mass index as long-term predictors of mortality in initially healthy men. J Gerontol A Biol Sci 2000;55:M168-73.

29 Rantanen T, Guralnik JM, Foley D, et al. Midlife hand grip strength as a predictor of old age disability. JAMA 1999;281:558-60.

30 Rankinen T, Perusse L, Rauramaa R, et al. The human gene map for performance and health-related fitness phenotypes: the 2001 update. Med Sci Sports Exerc 2002;34:1219-33.

31 Seeman TE, Unger JB, McAvay G, et al. Self-efficacy beliefs and perceived declines in functional ability: MacArthur studies of successful aging J Gerontol B Psychol Sci Soc Sci 1999;54:P214-22.

32 Torgen M, Punnett L, Alfredsson L, et al. Physical capacity in relation to present and past physical load at work: a study of 484 men and women aged 41 to 58 years. Am J Ind Med 1999;36:388-400

33 Ilmarinen J. Physical requirements associated with the work of aging workers in the European Union. Exp Aging Res 2002;28:7-23.

34 Karlqvist L, Leijon O, Harenstam A. Physical demands in working life and individual physical capacity. Eur J Appl Physiol 2003;89:536-47.

35 Martinez-Gonzalez MA, Varo JJ, Santos JL, et al. Prevalence of physical activity during leisure time in the European Union. Med Sci Sports Exerc 2001;33:1142-6.

36 Lantz PM, Lynch JW, House JS, et al. Socioeconomic disparities in health change in a longitudinal study of US adults: the role of health-risk behaviors. Soc Sci Med 2001;5:29-40.

37 Schriijvers CT, van de Mheen HD, Stronks K, et al. Socioeconomic inequalities in health in the working population: the contribution of working conditions. Int J Epidemiol 1998;27:1011-18. 